\title{
EFFECTS OF ARACHIDONIC ACID AND BRADYKININ ON THE CORONARY FLOW, RELEASE OF PGI 2 AND CARDIAC FUNCTIONS IN THE PERFUSED GUINEA-PIG HEART
}

\author{
Zen-ichi TERASHITA, Hiroshi FUKUI, Kohei NISHIKAWA, \\ Minoru HIRATA and Shintaro KIKUCHI \\ Central Research Division. Takeda Chemica! Industries, Ltd., \\ Yodogawa-ku, Osaka 532, Japan
}

Accepted December 23, 1981

\begin{abstract}
The contribution of prostacyclin $\left(\mathrm{PGI}_{2}\right)$ to the coronary vasodilating action of arachidonic acid (AA) and bradykinin (BK) was examined in isolated perfused guinea-pig hearts. The injection of AA (100 to 1,000 $\mathrm{ng}$ ) and BK (1 to $100 \mathrm{ng}$ ) into the heart resulted in a dose-dependent increase in the total amount of coronary flow and a release of 6 -ketoprostaglandin $F_{i a}$, a stable metabolite of $\mathrm{PGI}_{2}$. Both $A A$ and $B K$ showed weak positive chronotropic effects. In addition, higher doses ( 300 and $1,000 \mathrm{ng}$ ) of AA caused a transient reduction in the coronary flow rate, left ventricular systolic pressure, and left ventricular $\mathrm{dp} / \mathrm{dt}$. The changes in coronary flow, release of $\mathrm{PGl}_{2}$, and all cardiodynamic parameters induced by $A A$ were abolished by pretreatment of the preparation with diclofenac$\mathrm{Na}$. On the other hand, the BK-induced increase in coronary flow rate was only partially reduced by diclofenac- $\mathrm{Na}$ when the release of 6 -ketoprostaglandin $F_{1 a}$ was completely inhibited. It is concluded that in isolated perfused guinea-pig hearts. $B K$ has both $P G I_{2}$-independent and $P G I_{2}$ dependent coronary vasodilating actions; the latter action is less than $25 \%$. and the coronary vasodilating action of $\mathrm{AA}$ is mainly mediated via $\mathrm{PGI}_{2}$.
\end{abstract}

Arachidonic acid (A, ) and bradykinin (BK) have potent coronary vasodilating actions in isolated mammalian hearts (1, 2). The vasodilating action of $A A$ is attributed to a metabolic product of AA, prostacyclin $\left(P G I_{2}\right)$ (3). which has been described as being a prostaglandin-like substance (PLS). On the other hand, the mechanism for the coronary vasodilating action of BK remains obscure. Needleman et al. (2) suggested that the BK-induced coronary vasodilation seen in isolated rabbit heart preparations was mediated via the release of prostaglandins. Later, it was argued that $\mathrm{PGI}_{2}$ might play a main role in the coronary action of $B K$ in isolated rabbit hearts (4). Recently, however,
Schror et al. provided the evidence for an additional $\mathrm{PGI}_{2}$-independent mechanism of coronary vasodilation, as induced by $B K$ in guinea-pig hearts (5). In these studies, the release of $\mathrm{PGI}_{2}$-like substance was estimated by bioassay, and a quantitative relation between coronary vasodilation and $\mathrm{PGI}_{2}$ release following injection of $\mathrm{BK}$ was not studied in detail.

We now report our findings of the quantitative relation between coronary vasodilation and release of $\mathrm{PGI}_{2}$ as induced by $A A$ or BK. $\mathrm{PGI}_{2}$ was measured by the radioimmunoassay of 6-keto-prostaglandin $F_{1 \infty}$ (6-keto-PGF $F_{1 \infty}$ ), a stable derivative of $\mathrm{PGI}_{2}$. The cardiohemodynamic effects of both compounds 
were also studied

\section{MATERIALS AND METHODS}

The isolated guinea-pig heart preparation was made according to the method of Langendorff with a slight modification (6). In brief, male guinea pigs. weighing about $300 \mathrm{~g}$. were sacrificed by a blow on the head about $20 \mathrm{~min}$ after i.p. administration of $1.000 \mathrm{U} / \mathrm{kg}$ of heparin. A thoracotomy was done, and the heart immediately placed in ice-cold Krebs-Ringer bicarbonate solution composed of (mM) $127 \mathrm{NaCl}, 4.7 \mathrm{KCl}$. $2.5 \mathrm{CaCl}_{2}, 1.2 \mathrm{KH}_{2} \mathrm{PO}_{4}, 25 \mathrm{NaHCO}_{3}, 2.0$ sodium pyruvate and 5.5 glucose, and oxygenated with $97 \% \mathrm{O}_{2}-3 \% \mathrm{CO}_{2}(\mathrm{pH} \mathrm{7.4)}$. After removing perivascular tissues, a polyethylene cannula was inserted retrogradely into the aorta. A urethane polymer balloon connected to a glass tube was inserted into the left ventricular cavity through an incision of the left auricle. The heart was suspended in a chamber maintained at $37^{\circ} \mathrm{C}$. To measure the coronary flow rate, a cannulating type flow probe (inner diameter of $2 \mathrm{~mm}$ ) of an electromagnetic flowmeter (Nihon Kohden, MF-26) was placed just above the aortic cannula. The left ventricular isovolumetric pressure was recorded with a pressure transducer (Nihon Kohden, MPU$0.5)$ connected to the intraventricular balloon which was filled with physiological saline. The diastolic pressure was adjusted to lower than $10 \mathrm{mmHg}$ so that the pulse pressure would attain the maximum. The heart rate was recorded from left ventricular pressure pulses with a cardiotachometer (Nihon Kohden, RT-2). The left ventricular pressure $\mathrm{dp} / \mathrm{dt}$ was recorded through an electronic differential circuit with a time constant of $2.5 \mathrm{msec}$. The preparation was perfused at a constant perfusion pressure of $750 \mathrm{~mm} \mathrm{H}_{2} \mathrm{O}$ with the modified Krebs-Ringer bicarbonate solution described above, warmed to $37^{\circ} \mathrm{C}$. and aerated with $97 \% \mathrm{O}_{2}-3 \% \mathrm{CO}_{2}$. Experi- ments were started after a 20-30 min equilibration period. Only one dose-response relation for either $A A$ or $B K$ was determined in each preparation. AA and BK were dissolved in saline $(200 \mu \mathrm{l})$ and injected in a bolus fashion $(0.2 \mathrm{ml})$ into the coronary perfusion system. About $20 \mathrm{~min}$ after the injection of the highest dose of $A A$ or $B K$, the heart preparation was treated for $5 \mathrm{~min}$ with diclofenac- $\mathrm{Na}$ (finat concentration, $1 \mu \mathrm{g} / \mathrm{ml}$ ), a cyclooxygenase inhibitor (7), and then $A A$ or $B K$ was injected again under the continuous infusion of diclofenac-Na. Diclofenac-Na induced no changes in the basal coronary flow rate.

Effects of both agents on coronary flow were expressed by two ways as follows: 1) The changes from the basal coronary flow rate were shown as delta coronary flow rate $(\mathrm{ml} / \mathrm{min})$. 2) Total increase in coronary flow ( $\mathrm{ml}$ ) was estimated by determining the area under the curve of coronary flow increased by both agents.

Preparation of the antiserum for 6-ketoPGF $_{1 \text { a: }}$ Three $\mathrm{mg}$ of 6 -keto-PGF $F_{1 \text { w }}$ was conjugated to $4 \mathrm{mg}$ of bovine serum albumin (BSA) using water soluble carbodiimide following a method similar to that used in the case of $\mathrm{PGF}_{2}(8,9)$. The conjugate was purified by repeated dialysis against distilled water, lyophilized, and stored at $-20^{\circ} \mathrm{C}$ until use. An emulsion of the conjugate ( $1 \mathrm{mg}$ in $1 \mathrm{ml}$ of saline) in an equal volume of Freund's complete adjuvant was given s.c. at various sites on the back of one male albino rabbit once a week for 4 weeks, and thereafter, it was injected once a month for 3 months. The antiserum was prepared one month after the last immunization. The dilution of the antiserum which gives about $50 \%$ binding to ${ }^{3} \mathrm{H}$-6-keto-PGF 1 was $1: 1,000$. Radioimmunoassay with this antiserum enabled detection of 10 to $1,000 \mathrm{pg}$ of 6 -keto-PGF $\mathrm{F}_{1 \alpha}$. Cross reactivities of the antiserum with various prostaglandins and thromboxane $B_{2}$ 
$\left(\mathrm{TXB}_{2}\right)$ tested were less than $0.1 \%$ for $\mathrm{PGA}_{2}$. $P G D_{2}$ and $T X B_{2}, 1.8 \%$ for $P G E_{1}, 1.3 \%$ for $\mathrm{PGE}_{2}$ and $4.5 \%$ for $P \mathrm{PG}_{2}$.

Radioimmunoassay of 6-keto-PGF . $_{1 \text { in }}$ the perfusate: The perfusate was serially collected for $30 \mathrm{sec}$ just before and every $30 \mathrm{sec}$ starting just after injection of test agents and until the coronary flow rate returned to the initial level. The volume of the perfusate was measured with a graduated glass cylinder. After mixing well, $1 \mathrm{ml}$ of the effluent was adjusted to $\mathrm{pH} 3.5$ with $1 \mathrm{~N}$ $\mathrm{HCl}$, extracted with 4 volumes of ethyl acetate, and 6-keto-PGF $F_{1}$ determined by radioimmunoassay. The rabbit antiserum to 6-keto-PGF $F_{1}$ was diluted 1:1.000 with buffer $1(0.1 \mathrm{M}$ phosphate buffer at $\mathrm{pH} 7.5$ containing $0.1 \%$ gelatin. $0.9 \% \quad \mathrm{NaCl}$ and $\left.0.01 \% \mathrm{NaN}_{3}\right)$. The authentic 6 -keto-PGF $(10-1.000 \mathrm{pg})$ for the standard curve was dissolved in $50 \mu$ of buffer 1 . A $0.25 \mathrm{ml}$ aliquot of the extract was dried with $\mathrm{N}_{2}$ gas and dissolved in $50 \mu$ of buffer I. ${ }^{3} \mathrm{H}-6$ Keto-PGF in buffer I $(10.000 \mathrm{cpm} / 100$, l) was added to the extract solution. after which the $50 \mu$ of diluted rabhit antiserum was added. The tubes were shaken for $15 \mathrm{sec}$ and incubated for $1 \mathrm{hr}$ at $25^{\circ} \mathrm{C}$ and then for $16-20 \mathrm{hr}$ at $4^{\circ} \mathrm{C}$.

To separate the antiserum-bound and -free ${ }^{3} \mathrm{H}-6$-keto-PGF ${ }_{1 \alpha}$. dextran-coated charcoal ( $0.1 \mathrm{ml}$ of buffer I containing $2.5 \mathrm{mg}$ charcoal and $0.25 \mathrm{mg}$ dextran) was added to each tube and mixed for $15 \mathrm{sec}$. The tubes were left standing on ice for 10 mir followed by centrifugation for $5 \mathrm{~min}$ at $3,000 \mathrm{rpm}$ at $0-4^{\circ} \mathrm{C}$. The radioactivity of the supernatant $(180$ /l) was measured in $4 \mathrm{ml}$ of ACS 11 scintillator with a scintillation counter (LKB1216. Rackbeta). The counts of antiserum blank tubes, containing no antiserum. were subtracted from the counts of all other tubes as nonspecific binding. The standard curve was plotted as a function of logit versus the amount of anthentic 6-keto-PGF $F_{\text {w }}$ and the binding in each sample was compared to the standard curve. The recovery of 6-keto$P G_{1}$ in this method was $77.6 \pm 1.7 \%$ $(n=3)$.

Materilas: Materilas used were ${ }^{3} \mathrm{H}-6$ keto-PGF $(100 \mathrm{Ci} / \mathrm{mmole}$. New England Nuclear, U.S.A.), arachidonic acid (Sigma, U.S.A.), 6-keto-PGF $F_{10}$ (synthesized in this Chemical Laboratories), bradykinin (Protein Research Foundation, Japan), diclofenac-Na (extracted from Voltaren ${ }^{\circledR}$. Fujisawa, Japan). dextran (Pharmacia Fine Chemicals, U.S.A.), charcoal (Norit A. American Norit, U.S.A.), gelatin (Merck, Germany), $\mathrm{NaN}_{3}$ (Wako Pure Chemicals, Japan), 1-ethyl-3-(3dimethylaminopropyl)-carbodiimide hydrochloride (Nakarai Chemical, Japan), BSA (Miles Laboratories, U.S.A.), ACS II (Amersham, U.S.A.), and ethyl acetate (Wako Pure Chemical, Japan).

Statistical analysis: Values presented in this paper are the meantS.E.M. The Student $s$ t-test (paired) was used. Differences with $P<0.05$ were considered to be statistically significant: ${ }^{*} P<0.05 .{ }^{* *} P<0.01$.

\section{RESULTS}

Effects of arachidonic acid on coronary flow, release of 6-keto-PGF - $_{10}$ and cardiac parameters: The time course of the AAinduced increase in the coronary flow (delta coronary flow) and the release of 6-keto$P G F_{1 \infty}$ are shown in Fig. 1 and Table 1. The basal coronary flow rate was about $7 \mathrm{ml} / \mathrm{min}$. $\mathrm{AA}$ at doses of 100 and $300 \mathrm{ng}$ caused a dose-dependent increase in the maximum delta coronary flow, but the maximum delta coronary flow induced by $1,000 \mathrm{ng}$ of $\mathrm{AA}$ was lower than that by $300 \mathrm{ng}$ of AA. The higher doses ( 300 and $1.000 \mathrm{ng}$ ) induced a transient, dose-dependent reduction in the coronary flow rate. The maximum delta coronary flow induced by $1,000 \mathrm{ng}$ of $A \mathrm{~A}$ was less but longer-lasting than that by $300 \mathrm{ng}$ of AA. Thus, total increases in 
coronary flow induced by these 3 doses of AA were dose-dependent. The basal release of 6 -keto-PGF w was negligible. When the heart was stimulated with AA, 6-keto$P G F_{1 \alpha}$ was released immediately following AA injection in a dose related manner, and its maximum release was seen in the first $30 \mathrm{sec}$ collection period. A highly significant cor-

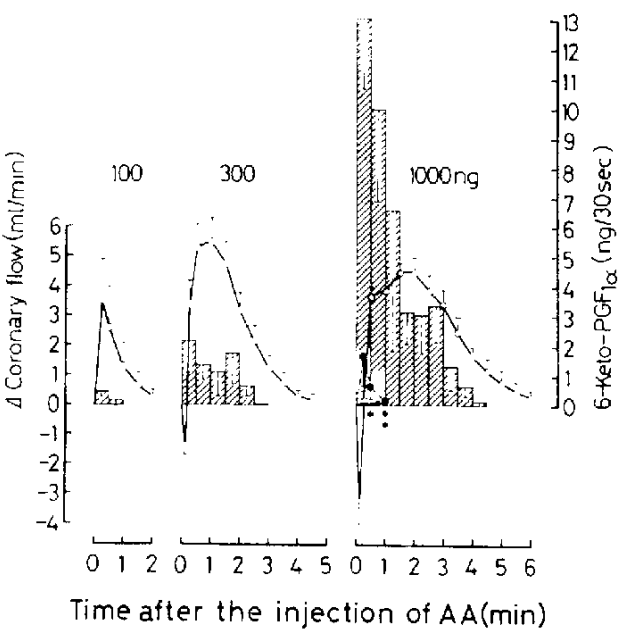

Fig. 1. Effects of arachidonic acid (AA) on delta coronary flow and release of 6 -keto-PGF ${ }_{i \alpha}$ in the isolated perfused guinea-pig heart with or without diclofenac- $\mathrm{Na} . \mathrm{O}-\mathrm{O} J$ coronary flow without diclofenac- $\mathrm{Na}, \cdots \cdot \mathrm{A}$ coronary flow with diclofenac- $\mathrm{Na}(1 \mu \mathrm{g} / \mathrm{ml})$. WII/T the release of 6 -keto-PGF « without diclofenac- $\mathrm{Na}$. the release of 6 -keto-PGF a with diclofenac-Na. relation was observed between the total increase in coronary flow and the total amount of 6-keto-PGF $F_{1 \infty}$ released (Fig. 2). Diclofenac- $\mathrm{Na}$ significantly inhibited both the transient reduction and the following increase in coronary flow rate and the release of 6 -keto-PGF $F_{1 \infty}$ induced by $1,000 \mathrm{ng}$ of AA. The total increase in coronary flow induced by $1.000 \mathrm{ng}$ of AA under the continuous infusion of diclofenac- $\mathrm{Na}$ was very small (Table 1).

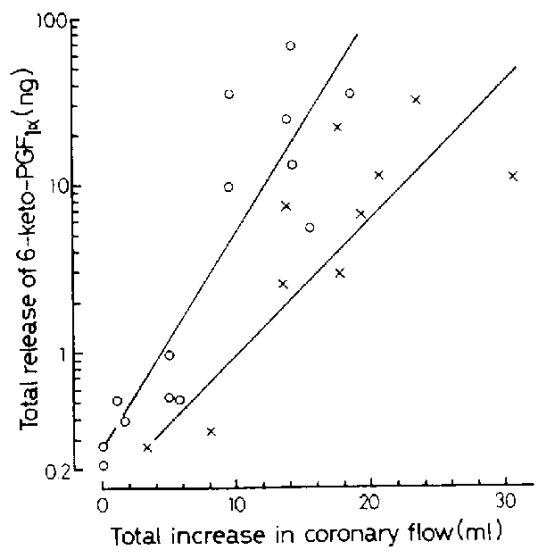

Fig. 2. The correlation between the increase in coronary flow and the release of 6 -keto-PGF ${ }_{1 \alpha}$ in the isolated perfused guinea-pig heart following stimulation with arachidonic acid (AA) or bradykinin (BK). AA (O): $y=1.35 x$ -0.59, $r=0.89 . \quad P<0.01, \quad B K(x): \quad y=1.17 x$ $-0.50, r=0.77, P<0.01$.

Table 1. Effects of arachidonic acid and bradykinin on the coronary flow and the release of 6 -keto- $\mathrm{PGF}_{1^{\alpha}}$ in isolated perfused guinea pig hearts

\begin{tabular}{|c|c|c|c|c|c|c|}
\hline \multirow{3}{*}{$\begin{array}{l}\text { Maximum delta coronary } \\
\text { flow (ml/min) }\end{array}$} & \multicolumn{3}{|c|}{ Arachidonic acid (ng) $(n=4)$} & \multicolumn{3}{|c|}{ Bradykinin (ng) } \\
\hline & 100 & 300 & 1.000 & $1(n=3)$ & $10(n=4)$ & $100(n=5)$ \\
\hline & $3.5 \pm 1.4$ & $5.5 \pm 0.8$ & $4.5 \pm 0.3$ & $4.4 \pm 0.8$ & $5.7 \pm 0.7$ & $4.9 \pm 0.6$ \\
\hline $\begin{array}{l}\text { Total increase in coronary } \\
\text { flow }(\mathrm{ml})\end{array}$ & $3.0 \pm 1.2$ & $11.3 \pm 2.3$ & $14.3 \pm 1.8$ & $3.5 \pm 0.1$ & $13.4 \pm 2.0$ & $22.9 \pm 2.7$ \\
\hline (after diclofenac- $\mathrm{Na}$ ) & & & $(0.9 \pm 0.6)$ & $(3.4 \pm 0.2)$ & $(10.2 \pm 2.0)$ & $(18.2 \pm 3.0)$ \\
\hline $\begin{array}{l}\text { Total amounts of released } \\
6 \text {-keto-PGF }{ }_{1 \text { a }}(\mathrm{ng})\end{array}$ & $0.52 \pm 0.16$ & $7.24 \pm 2.71$ & $32.16 \pm 3.65$ & $0.09 \pm 0.09$ & $3.36 \pm 1.53$ & $17.33 \pm 4.78$ \\
\hline (after diclofenac-Na) & & & $(0.20 \pm 0.12)$ & & & $(0.34 \pm 0.22)$ \\
\hline
\end{tabular}




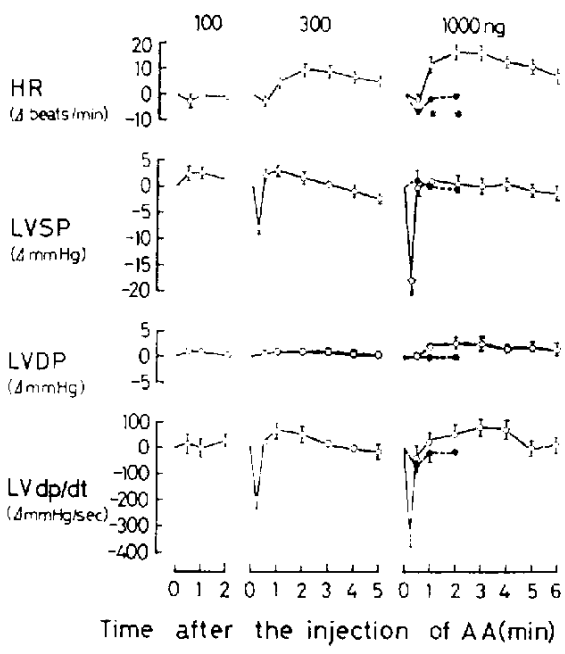

Fig. 3. Effects of arachidonic acid (AA) on cardiohemodynamic parameters in the isolated perfused guinea-pig heart with or without diclofenac-Na. O O without diclofenac-Na, - with diclofenac-Na $(1 \mu \mathrm{g} / \mathrm{ml})$. Abbreviations: HR, heart rate; LVSP, left ventricular systolic pressure: LVDP. left ventricular diastolic pressure: $L V d p / d t$, left ventricular $d p / d t$.

Figure 3 shows the effect of AA on the heart rate (HR), left ventricular systolic pressure (LVSP), left ventricular diastolic pressure (LVDS). and LVdp/dt. Three hundred and $1,000 \mathrm{ng}$ of AA showed positive chronotropic effects. The AA-induced transient decrease in the LVSP and LVdp/dt paralleled the decrease in the coronary flow in the early phase as seen in Fig. 1. LVDP was slightly increased with $1,000 \mathrm{ng}$ of AA. These changes in cardiac parameters induced by $1,000 \mathrm{ng}$ of AA were completely inhibited by pretreatment with diclofenac- $\mathrm{Na}$.

Effects of bradykinin on coronary flow. release of 6-keto-PGF $F_{10}$ and cardiac parameters: Figure 4 shows the effect of $B K$ on the coronary flow rate (delta coronary flow) and the release of 6 -keto-PGF $F_{10}$. The maximum delta coronary flow with $100 \mathrm{ng}$ of BK was lower than that with 10 ng of BK, but the coronary flow increasing action lasted longer with $100 \mathrm{ng}$ of BK than with $10 \mathrm{ng}$ of

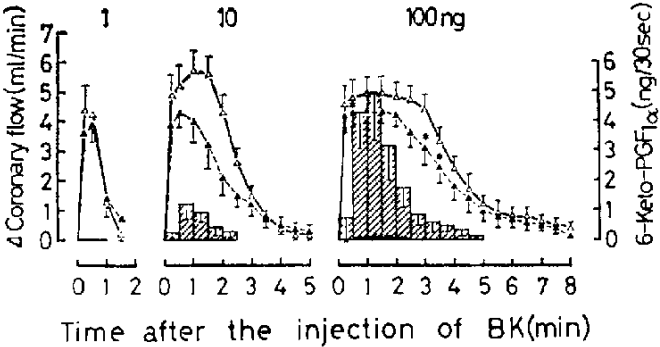

Fig. 4. Effects of bradykinin (BK) on delta coronary flow and release of 6 -keto-PGF $F_{1 a}$ in the isolated perfused guinea-pig heart. $\triangle-\triangle \Delta$ coronary flow without diclofenac- $\mathrm{Na}, \boldsymbol{\Delta} \cdots \cdots . . \Delta$ coronary flow with diclofenac- $\mathrm{Na}(1 \mu \mathrm{g} / \mathrm{ml})$, WUizs the release of 6-keto-PGF $F_{1 \alpha}$ without diclofenac- $\mathrm{Na}$, the release of 6 -keto-PGF ${ }_{1 \alpha}$ with diclofenac-Na.

BK. Thus, the total increase in coronary flow induced by these doses of $B K$ were dose-dependent (Table 1). 6-keto-PGF was not significantly released by $1 \mathrm{ng}$ of $B K$, but was released dose-dependently by 10 and $100 \mathrm{ng}$ of BK (Table 1). The relationship between the total increase in coronary flow and total amounts of 6-keto-PGF 1 ra released is shown in Fig. 2. The release of 6-keto$P \mathrm{PF}_{1 \text { a }}$ induced by $\mathrm{BK}$ was less than that by $A A$, but the total increase in coronary flow induced by $B K$ was more than that by $A A$. The patterns of 6 -keto-PGF 1w $_{10}$ release and the increase in coronary flow differed between the administration of $A A$ and $B K$. Following stimulation with $B K$, the release of 6 -ketoPGF $F_{1 \text { r }}$ was scanty in the first $30 \mathrm{sec}$, but the coronary flow increased rapidly and reached the submaximum flow in the first $30 \mathrm{sec}$. Namely, the increase in the coronary flow preceded increases in the release of 6-keto$P G F_{1 \text { a. }}$. The difference in the time course of the increase in coronary flow and the release of 6-keto-PGF $F_{10}$ was most apparent with the highest doses of $A A$ and $B K$. The release of 6 -keto-PGF - $_{\text {os }}$ induced by $100 \mathrm{ng}$ of $\mathrm{BK}$ was completely inhibited by diclofenac- $\mathrm{Na}$. whereas the increase in the delta coronary flow was only partially but significantly 


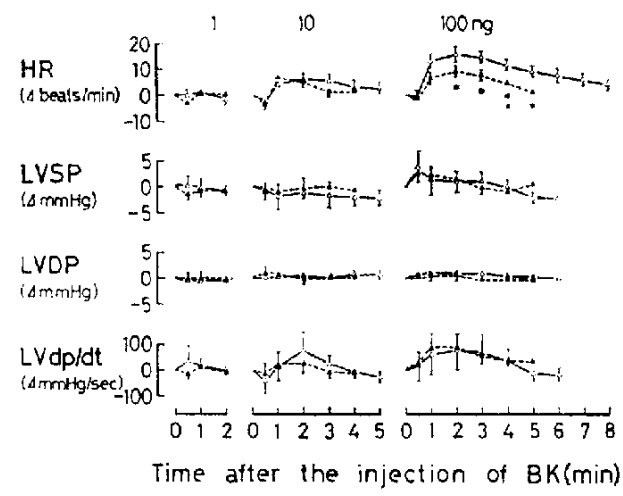

Fig. 5. Effects of bradykinin (BK) on cardiohemodynamic parameters in the isolated perfused guinea-pig heart. $\triangle-\Delta$ with diclofenac- $\mathrm{Na}$, $\Delta \cdot \mathbf{\Delta}$ with diclofenac-Na. Abbreviations $H R$, heart rate: LVSP, left ventricular systolic pressure; LVDP, left ventricular diastolic pressure: LVdp/dt, left ventricular $\mathrm{dp} / \mathrm{dt}$.

reduced by diclofenac- $\mathrm{Na}$ at the highest dose of BK (Table 1).

Figure 5 shows the effect of BK on cardiac function. The lowest dose (1 ng) of BK had little effect on HR, LVSP. LVDP, and LVdp/dt. At doses of 10 and $100 \mathrm{ng}$. BK caused a sustained increase in $H R$ and a slight increase in LVdp/dt. Only $100 \mathrm{ng}$ of BK induced a slight and transient increase of LVSP. Diclofenac-Na did not affect the positive chronotropic action induced by $10 \mathrm{ng}$ of $\mathrm{BK}$ but partially inhibited that induced by $100 \mathrm{ng}$ of BK.

\section{DISCUSSION}

Schrör et al. (5) presented the evidence for an additional $\mathrm{PGI}_{2}$-independent mechanism for the coronary vasodilating action of BK. In these studies, however, the contribution of $\mathrm{PGI}_{2}$ to the BK-induced coronary vasodilation was not examined quantitatively. In the present study, we attempted to clarify the quantitative contribution of $\mathrm{PGI}_{2}$ to the BK-induced coronary vasodilation in isolated perfused guinea-pig heart using radioimmunoassay of 6-keto-PGF Although PGs other than 6-keto-PGF $F_{1 a}$ were not measured in the present experiments, it has been known that both $P G D_{2}$ and $P G F_{2}$ decrease coronary flow. $P G E_{2}$ has less potent coronary dilating action than $\mathrm{PGI}_{2}(10)$, and $P G I_{2}$ is the main metabolite of $A A$ in the heart (4). Thus, we could focus on the contribution of the released $\mathrm{PGI}_{2}$ to coronary vasodilation induced by $A A$ and $B K$ in isolated guinea-pig hearts. As shown in Fig. 4, diclofenac- $\mathrm{Na}$ completely inhibited the release of $\mathrm{PGI}_{2}$, but only partially inhibited the delta increase in coronary flow induced by 10 and $100 \mathrm{ng}$ of BK. The degrees of inhibition of the BK-induced total increase in coronary flow with diclofenac- $\mathrm{Na}$ were $2.4 \pm 9.1,25.7 \pm 9.9$ and $19.5 \pm 7.8 \%$ for 1,10 and 100 ng of BK, respectively. These results suggest that though higher doses of $B K(10$. $100 \mathrm{ng}$ ) certainly release $\mathrm{PGI}_{2}$ from guineapig hearts, the contribution of the released $\mathrm{PGI}_{2}$ to the $\mathrm{BK}$-induced coronary vasodilation is relatively small (less than 25\%). Thus, the $\mathrm{PGI}_{2}$-independent mechanism may play a main role in the BK-induced coronary vasodilation in isolated guinea-pig hearts. The $\mathrm{PGI}_{2}$-independent mechanism seems to act faster than the $\mathrm{PGI}_{2}$-dependent one in the coronary vasodilation since the increase in coronary flow preceded the release of 6-keto-PGF ${ }_{1 \infty}$ (Fig. 4).

The maximum delta coronary flow induced by $100 \mathrm{ng}$ of $B K$ was lower than that by $10 \mathrm{ng}$ of BK. The mechanism of this phenomenon is unclear. The increase in heart rate induced by $100 \mathrm{ng}$ of BK was partially but significantly inhibited by diclofenac-Na (Fig. 5). This positive chronotropic action of $\mathrm{BK}$ may be mediated via $P G E_{2}$ since in isolated guineapig hearts, the positive chronotropic effect of $\mathrm{PGE}_{2}$ is much more potent than that of $P \mathrm{PI}_{2}$, and both $P G F_{2}$ and $P G D_{2}$ have negative effects (10).

The AA-induced increase in coronary flow seems to be due to $\mathrm{PGI}_{2}$ synthesized from the injected AA since there was a highly 
significant correlation between the total increase in coronary flow and the total amount of 6 -keto-PGF: a released following injection of 3 doses of AA. The maximum delta coronary flow induced by $1.000 \mathrm{ng}$ of AA was lower than that by $300 \mathrm{ng}$. This phenomenon might have resulted from the masking of the action of $P G l_{2}$ to increase coronary flow by a marked dose-dependent. transient reduction in coronary flow seen with higher doses of $A A$. The transient reduction in coronary flow at higher doses of AA, as inhibited by diclofenac-Na, may be due to a coronary vasoconstricting action of $P G$ endoperoxides synthesized from the injection of AA (3). We have already reported that in isolated guinea-pig hearts, exogenous $\mathrm{PGH}_{2}$ (one of the $P G$ endoperoxides) reduces coronary flow rate (11). The AA-induced positive chronotropic effects may also be due to $P G E_{2}$ and/or $P G$ endoperoxides.

A difference in the time course for 6 -keto$P G F_{1}$ release between $A A$ and $B K$ suggests that $A A$ is directly transformed to $P G I_{2}$ and other PGs through $P G$ endoperoxides. whereas the release of PGs induced by $B K$ needs an additional step. probably an activation of phospholipase $A_{2}$ (12)

AA produced the decrease in the LVSP and LVdp/dt in parallel with the decrease in the coronary flow, suggesting that the depression of both parameters might be secondary to the decrease in the coronary flow in the early phase following injection of AA. LVDP was slightly increased following $1,000 \mathrm{ng}$ of AA. This mechanism is unclear. but the increase in LVDP might be the extravascular component of the coronary resistance.

In conclusion. BK has both the $\mathrm{PGI}_{2}{ }^{-}$ independent and $\mathrm{PGl}_{2}$-dependent coronary vasodilating actions in isolated perfused guinea-pig hearts, but the contribution of the latter mechanism is small (less than $25 \%$ ). whereas the coronary vasodilating action of
AA is mediated mainly via $\mathrm{PGI}_{2}$

Acknowledgements: We thank Drs. M. Takaoki, K. Sudo, and T. Terao of this Central Research Division for developing the radioimmunoassay for 6-keto $\mathrm{PGF}_{1}$ and Dr. K. Kikuchi for critical discussion in preparing this manuscript.

\section{REFERENCES}

1) Needleman, P.: The synthesis and function of prostaglandins in the heart. Fedn Proc. 35 , 2376-2381 (1976)

2) Needleman, P., Key, S.L., Denny, S.E., Isakson, P.C. and Marshall, G.R.: Mechanism and modification of bradykinin-induced coronary vasodilation. Proc. natn. Acad. Sci. U.S.A. 72, 2060-2063 (1975)

3) Schrör, K., Moncada, S., Ubatuba, E.B. and Vane, J.R.: Transformation of arachidonic acid and prostaglandin endoperoxides by the guinea pig heart. Formation of RCS and prostacyclin. Europ. J. Pharmacol. 47, 103-114 (1978)

4) Needleman, P., Bronson, S.D., Wyche, A., Sivakoff, M. and Nicolaou, K.C.: Cardiac and renal prostaglandin $\left.\right|_{\%}$. Biosynthesis and biological effects in isolated perfused rabbit tissues. J. clin. Invest. 61, 839-849 (1978)

5) Schrör, K., Metz, U. and Krebs, R.: The bradykinin-induced coronary vasodilation. Evidence for an additional prostacyclinindependent mechanism. Naunyn-Schmiedeberg's Arch. Pharmacol. 307, 213-221 (1979)

6) Bünger, R., Haddy, F.J., Querengässer, A. and Gerlach, E: An isolated guinea pig heart preparation with in vivo like features. Pflügers Arch. 353, 317-326 (1975)

7) Ku, E.C., Wasvary, J.M. and Cash, W.D.: Diclofenac sodium (GP 45850, Voltaren), a potent inhibitor of prostaglandin synthetase. Biochem. Pharmacol. 24, 641-643 (1975)

8) Caldwell. B.V., Burstein, S., Brock, W.A and Speroff, L.: Radio-immunoassay of the prostaglandins. J. clin. Endocr. 33, 171-175 (1971)

9) Salman, J.A.: A radiommunoassay for 6 keto-prostaglandin $F_{1}$. Prostaglandins 15 , 383-397 (1978)

10) Allan, G. and Levi, R.; The cardiac effects of prostaglandins and thoif modification by tine prostaglandin antagonist N 0164. J. Pharmacol (xp. Ther. 214, $4549(1930)$

11) Terashita, Z., Fukui, H., Nishikawa, K., Hirata, 
M. and Kikuchi, S.: Coronary vasospastic action of thromboxane $A_{2}$ in isolated, working guinea pig hearts. Europ. J. Pharmacol. 53, 49-56(1978)

12) Vargaftig, B.B. and Hai, N.D.: Selective inhibition by mepacrine of the release of "rabbit aorta contracting substance" evoked by the administration of bradykinin. 3. Pharm. Pharmacol. 24, 159-161 (1972) 